\title{
Metaphors AND ACTIVITY
}

\author{
(Metáfora e Atividade)
}

Jacob L. MeY

(University of Southern Denmark, Odense)

\author{
Given its basis in the historical conditions \\ under which people live and engage in their worlds, \\ a study of communicative practice deals as much \\ with the actual doings of real agents as it does \\ with the systemic potentials of symbolic forms. \\ (Hanks 1996:231)
}

\begin{abstract}
This paper considers metaphor as a kind of activity in the spirit of Levinson's 'Activity Types' or of Mey's 'Pragmatic Acts'. Contrary to what has been suggested in the literature, metaphors neither belong exclusively to the domain of abstract reasoning (such as by analogy; Max Black), nor are they merely linguistic andlor psychological processes (of cognition; George Lakoff). Metaphors do not originate and live in the brain only, neither do they exclusively belong to some conceptual domain from which they can establish relations to other domains, or blend with them. Metaphors are primarily pragmatic activities. In my contribution, I will concentrate on the pragmatics of what is called 'embodiment': while metaphors represent, respectively support or illustrate, an activity that is performed by the total human being, the body part of the metaphoric deal is often neglected. Yet, as many researchers in the bumanities and the sciences have shown, the role of the body in solving problems through appropriate metaphoring cannot be overestimated. An embodied perspective on thought, and especially on metaphor, will allow us to form a better understanding of the things we do with words, when we use words to do things.
\end{abstract}

KEY-WORDS: the origin of metaphors; pragmatic activities; "embodiment".

RESUMO: Este artigo considera a metáfora um tipo de atividade no espírito dos "Tipos de Atividades" de Levinson ou dos "Atos Pragmáticos" de Mey. Contrariando o que tem sido sugerido pela literatura, as metáforas não pertencem exclusivamente ao domínio do raciocínio abstrato (por exemplo, por analogia; Max Black), nem são elas meramente

D.E.L.T.A., 22:Especial, 2006 (45-65) 
processos lingüísticos elou psicológicos (da cognição; George Lakoff). As metáforas não tem sua origem e vivem apenas no cérebro, nem pertencem exclusivamente a algum domínio conceitual, a partir do qual elas possam estabelecer relaçöes ou fusões com outros dominios.As metáforas são primordialmente atividades pragmáticas. Na minha contribuição, eu me concentrarei na pragmática do que tem sido denominado "embodiment" : apesar de metáforas representarem, respectivamente sustentarem ou ilustrarem uma atividade realizada pelo ser humano total, a parte corporal do empreendimento metafórico tem sido freqüentemente negligenciada. Ainda assim, como muitos pesquisadores nas ciências têm demonstrado, o papel do corpo na solução de problemas por meio da metaforização apropriada não pode ser superestimado. Uma perspectiva que considere o papel do corpo no pensamento, e especialmente na metáfora, nos permitirão compreender melhor os atos que realizamos com palavras, quando usamos palavras para realizar atos. PALAVRAS-CHAVE: a origem das metáforas; atos pragmáticos; o papel do corpo bumano na metaforização.

\section{Introduction}

In his 1996 work, Language and communicative practice, the linguistic anthropologist Bill Hanks points to the importance of symbolic activities in what we usually call practice. Practice is understood as the interaction of humans with the world (another term is 'praxis'); it has a dual aspect, that of the human meeting the world, and that of the world meeting the human. Most of the time, we concentrate on the way we, as humans, can make the world appear for us in a represented, and representative, form ('the word'); this is the one half of our symbolic activity. But as the primordial animal symbolicum (in Ernst Cassirer's well-known formula), we also have to do the other half of our practical duty: we have to let 'the world' represent ourselves and our activities. Doing this, we embody our activities: not only does the word become a symbol of the world, but also, the world becomes an icon of ourselves. As Gibbs has expressed it, "cognition is what happens when the body meets the world" (Gibbs 1999:155); - but we need to ask, in addition: what happens when the world meets the body?

In addition, we have to widen our perspective: not only does the body meet world, and does the world meet body; the human totality comprises both mind and body, or better, their unity (the body/mind), which may be read in either direction, as either the embodied mind or the 'mentalized' body. 
Cognition, understood as the meeting of body/mind and world, thus has a double aspect: on the one hand, the body/mind expresses the world symbolically (through all kinds of language); on the other, the world opens up to the body/mind iconically (through all kinds of 'affordances', in the sense of James J. Gibson, 1979). The two aspects are joined in our cognitive instrumentality, first of all in metaphor.

George Lakoff's well-known definition of metaphor 'seeing one concept in terms of another' (Lakoff \& Johnson 1980:52 et pass.) thus receives a more profound meaning, in that it must incorporate this dialectic movement between world and body, body and world. In metaphor, what we see is not only the mind in terms of the body, but also the body in terms of the mind. Not only do we understand the mind, using categories belonging to our bodily environment ('anger is heat'), but we also understand the body by using expressions belonging to the mental sphere ('when your knees start talking to you something, you'd better listen', in the words of an aerobics instructor in Austin, Texas). Basic to a more fertile conception of metaphor is this 'anchoring' in the world, more specifically in the world of our activities.

\section{A world of affordances}

Going back to Hanks' quote in the beginning of this paper, I would like to stress, with the author, the importance of the feasibility aspect in metaphoring. Anchoring our metaphors in an embodied world means more than just relating them superficially to a 'real' activity. As Hanks says, " ... actors, ... have a sense of what could be done under given circumstances and what is either impossible or likely to fail" (1996:231; italics original). In other words, in acting, we pre-view what we can do, and this vision preforms our actions.

When it comes to metaphor, this line of reasoning implies two things:

- one, the idea that metaphors are mainly conceptual, internal-mental connections between conceptual representations misses out on an important aspect of our understanding of metaphor;

- two, the actual use of metaphors itself cannot be satisfactorily explained by reference to purely conceptual processes. 
Gibbs remarks that it would be wrong to assume that "the development of conceptual metaphors arise[s] only from internal representations and not from people's embodied, cultural interactions with the real-world" (1999:157). The question is now how to define and describe those interactions and this embodiment. Doing so will provide us with a better understanding of metaphor as a cognitive process, but also with better ability to use metaphor as a 'tool', by condensing and 'off-loading' (Gibbs' expression; ibid.) our mental and other activities onto the embodied space represented by the metaphor. For instance, the way we 'metaphorize' our daily computer-related activities is of great importance both for our own understanding of our work and for the success with which we employ the computer, respectively the damage we inflict upon ourselves by mis-using it or blindly obeying its injunctions and prohibitions. To see this better, consider the following.

Actually, part of the trouble surrounding our current usage of computers stems from the fact that they are designed to take away much of the 'overriding' affordances that we have in dealing with other, more old-fashioned tools: when a pencil is blunt, we sharpen it (using a pencil sharpener or just a knife), but when some of the keys on our computer don't respond to our touch, we take the whole thing to the computer man, who probably will tell you to replace the entire keyboard - or maybe get yourself a new laptop. In this way, the very nature of the metaphor ('the computer as a tool') reflects the activities and affordances that surround the usage of the tool. A proper understanding of the 'toolness' will enable us to deal with our problems in a better way; in Gibbs' words, "... metaphors are 'off-loaded' into the ... world to enable people to better solve problems, make decisions, and perform skilled action ..." (1999:157; see also Mey 1987, 1996, 2002 on the computer's 'toolness'). An application of this way of thinking will be discussed in the next section.

\section{Metaphors at work}

The German/US sociologist Karin Knorr-Cetina has dedicated her professional life to the study of scientists' behavior when they, as she calls it 'manufacture knowledge'. ${ }^{1}$ She has been able to show that, contrary to

\footnotetext{
1 Note that there is nothing per se odious in this expression, as if it e.g. were to imply the scien-
} tists' 'fabricating', not 'discovering' facts (whatever one may understand by the latter term). 
common assumptions, the scientists do not just uniformly react to 'data', but that the way they approach their objects and set up their experiments, then monitor them and measure the results, is vastly different from science to science.

For example, in high energy physics (HEP), the scientists rarely interact with the data: an experiment is set up and runs for a number of years, and the data are studied not so much by direct observation (which would be impossible anyway) as by studying the behavior of the experimental apparatus (especially of the devices called 'detectors') and the scientists' reaction to, interpretation of, and reasoning about, the apparatus and its properties (its 'behavior', as Knorr-Cetina, in a consciously anthropomorphic terminology, calls it).

In contrast to what happens in a molecular biology laboratory, for instance, where the scientists operate more directly with 'objects' that ideally can be measured, in the high energy physics lab, the measurements in themselves are not significant. As Knorr-Cetina says,

"[p]urely experimental data 'means nothing by itself [in HEP]. Not only are there few quantities that can be measured relatively directly, but even those are not to be taken as they are. Experimental numbers are dependent upon a particular detector configuration and on the criteria applied in extracting information from the detector. Another detector, another set of criteria, yields other measurements." (Knorr-Cetina 1999:53).

Somewhat superficially, one could claim that in this kind of physics, 'negative knowledge' (the knowledge about what things are not, or what they do not represent) is more important (as it is in certain 'ways' of Buddhism) than 'positive' knowledge, knowledge about objects and what they 'really' are, or are supposed to be.

From another point of view, while both molecular biology and high energy physics operate by sign interpretation (both sciences have to rely on certain signs that they have to interpret data), the physicist is much more prone to rely on the sign relation than is the molecular biologist, whose 'epistemic culture' is "orientated towards positive knowledge built from the manipulation of objects in an experiential regime that continuously turns sway from sign processes" (Knorr-Cetina 1999:80). 
And this is where metaphors step in to save the day. ${ }^{2}$ It is fascinating to read Knorr-Cetina's description of how the experimental high energy physicists, in trying to cope with their 'signs', invent all sorts of metaphoric relations, based on their interaction with the instruments and the 'data'. Here,

"the traditional concepts of a person, an actor, or a role are not sufficient to capture the structurings of reality within these experimental arenas. For example, it is not a physicist's role or the role of a machine that is at issue, but the definition of these objects as working components of the setting in relation to other components" (ibid.:113).

But how is this relation between the components achieved? The answer is: by creating metaphors that will capture the specific activities and objects that the physicists 'see' while doing their experiments. Consider again the instrument called a detector. A detector "qualifies as a sort of ultimate seeing device" (Knorr-Cetina, ibid.:114). The impact of the particles they record will in the end turn up as numbers on a digital counting unit. But in the interaction with these big machines (several stories high and weighing many tons; ibid.), a complex metaphorical world is created, in which the scientists treat the machine as a "competing athlete", whose "performance", or just "coping", is subject to various environmental and individual factors. Just like real athletes, the detector can be "doped", and it faces challenges from "hostile environments" obstructing its performance. In other words, the detector is metaphorically construed "as a physiological being" (KnorrCetina ibid.:114-115; italics original).

\section{Knorr-Cetina continues:}

"The agent appears to be supplemented by a kind of body with its own internal life and problems. Physiology comes into the picture when the detector is seen as continually changing. Detectors, like all of us, are slowly, but relentlessly 'aging'. In fact, they are aging in such a predictable manner that when for once in UA2 ['underground area 2', the experimental situation in which the author did her research] the calorimeter appeared to 'get younger', it caused quite a commotion in the experiment, and a thorough investigation of the 'problem' followed.... Detector aging can be accelerated by environmental conditions, as by radiation damage. Detectors not only age, but they are also 'unstable'. They are prone to sudden 'jumps' in their behavioral response, which may be environmentally triggered (for example,

\footnotetext{
2 Knorr-Cetina does not explicitly touch upon the subject of metaphoring, but speaks in a more general fashion about 'analogies'.
} 
by temperature changes), and they will, at times, 'act up'. Because of their aging and instabilities, detectors must be monitored. Monitoring also applies to the physiological states of a detector or parts of a detector, which are mostly described in terms of illness, disease, and death. Detectors and detector parts are said to be 'alive', 'dead', 'killed', or 'cannibalized'. They have a 'life expectancy' ('how long do they live?' is a question that may be asked with respect to certain parts), and their life may also be 'prolonged'. Furthermore, they may have 'diseases', 'be sick', 'ailing', or 'congested', suffer from poisoning', or 'go crazy'. In response to these predicaments and other occurrences, they may 'complain' of an illness, which is then 'diagnosed' and treated with 'antibiotics' and 'first aid'. 'The patient' may then 'die' and remain 'as dead as ever', or 'recuperate' and be 'cured' and 'healed'." (Knorr-Cetina 1999:116; see Figure 1: the detector as a physiological being (Knorr-Cetina 1999:117, fig. 5.2)

It is with the aid of such metaphorical constructions, which are based on their scientific activities and their interaction with the machine, that the physicists are able to handle their experiments, in spite of the apparent lack of 'input' of new data and the lack of direct measurements. As KnorrCetina remarks, the main difference in metaphoring between high energy physics and molecular biology is that while the former views machines as organisms, the latter turns organisms into machines (1999:114).

As we see from the above, the 'epistemic culture' (Knorr-Cetina's expression) surrounding a particular science can vary highly with the sciences involved. In any case, in its dealings with the science's results and methods, such a culture is highly metaphorical. But at the same time, it is based on the activities that go on in a particular branch of science, that is: on the ways human experimenters develop and exploit and lastly interpret their own techniques in relation to the experiments and the machinery involved, incorporating the certainties and uncertainties that characterize a science.

The next section will consider some of the implications of the above for the theory of metaphor itself.

\section{Metaphors as tools for cognition}

In an earlier work, Knorr-Cetina had already remarked that in the 'manufacturing of knowledge', the transformations did not result from their [the scientists'] conceptual interaction, but from a process of production and reproduction" (1981:57). 
The 'transformations' that she is talking about here are the changes and adjustments in ideas and procedures that happen during the course of an experiment or a series of experiments.

It is important to note that such changes in the 'ideology' of the tasks to be performed mostly have to do with analogies and metaphors. ${ }^{3}$ And the 'production' and 'reproduction' that she mentions have to be understood as parts of the continuous activities that constitute the setting up, maintaining, and running of a huge experimental project such as 'UA2'. ${ }^{4}$ In other words, the metaphors that the high energy physicists are using in the daily interaction at the project site do not originate in their 'heads', are not purely conceptual, but emanate from the body-mind and mind-body interaction that takes place when humans meet the world (read: when the physicists meet their detectors and other pieces of equipment).

Hence it would be a mistake to believe (with Lakoff and other cognitivists) that metaphoric activity has its origin and exerts its full sway in the sphere of conceptualizations (cf.: "the locus of metaphor is thought", Lakoff 1993:204). The 'domains' and 'mappings' that Lakoff and his associates talk about are not in the head, but out there where the 'mindbody' meets the world, as I said above. The following sections will pursue this point in more detail.

\subsection{Domains and mapping}

One of the most influential ideas that have been offered to deal with metaphors comes from work by George Lakoff and Mark Johnson (1980). These ideas have been further elaborated by Lakoff $(1987,1993)$ and independently applied to grammatical issues by cognitive linguists such as Ronald Langacker (1987/1991).

The basic notion here is that of a domain. In the 'source domain', certain general relations (of causal, consequential, spatial, temporal etc. nature)

\footnotetext{
Knorr-Cetina does not really distinguish here (1981) between analogy and metaphor. Most of the times, she uses the former term, but seems to include also the latter. Neither in her more recent work does she show familiarity with recent work in cognitive theory regarding metaphor.

4 UA2 (for 'underground area 2') is the huge collider experiment that has run at CERN ('Centre Européen de Recherches Nucléaires' at Geneva, Switzerland) from 1987 on.
} 
obtain. These relations are then transferred to another domain (the 'target domain'), where they are assigned a correspondence with the relations that are characteristic for that latter domain. To take one of Lakoff s well-known examples: the dimension of 'high' vs. 'low' (a spatial relation) is transferred to serve metaphorically as the expression of 'social status' (as in 'high class') or 'cost' (as in 'an upscale restaurant').

According to Lakoff, these relations are seen as taking place in the conceptual sphere: it is because of our conceptualizing one domain in terms of the other that we can have metaphors, which are nothing but ways to look at one phenomenon in the light (or 'in terms') of another (Lakoff \& Johnson 1980).

What neither Lakoff nor any of the other cognitive metaphoricists emphasize in their speculations is how all this happens, and in particular why these relations are paralleled, why the domains can be put into some particular metaphoric relation with one another, and so on. In other words, looking at metaphor uniquely as a conceptual relation, they fail to see its social aspects. And this is precisely where activity comes in.

I will illustrate the above by quoting from one of the classic works in the literature on metaphor, Lakoff \& Johnson (1980), where the idea is explicitly propounded that we structure our activities in accordance with the concepts we have in our heads. The following comes from a context where the authors have identified the target domain, that of 'having an argument' in terms of the domain of the source, 'waging a war':

"We talk about arguments that way because we conceive of them that way [viz., as WAR]-and we act according to the way we conceive of things" (1980:5)

To make this relationship plausible, the authors set up the following sequential reasoning (for which no justification whatever is offered):

"The concept is metaphorically structured, the activity is metaphorically structured, and, consequently the language is metaphorically structured". (ibid.)

Against this, I maintain that the activity comes first, and that our concepts are structured in accordance with that activity. It is because we 
actually argue as if we were waging a war, that we conceptualize of our 'arguments' as war, and not the other way 'round.'

The next section will deal more specifically with the role of language in metaphoring.

\subsection{The role oflanguage}

It would be a mistake, however, to believe that Lakoff and his followers are exclusively concentrating on the wording of the metaphor. Metaphors, Lakoff says, are

"not just a matter of language, but of thought and reason. The language is secondary. The mapping is primary in that it sanctions the use of source domain language and inference patterns for target domain concepts" (1993:208).

And in the earlier quote, cited above: "the locus of metaphor is thought", the continuation reads: "not language" (ibid.:204)

While I agree with Lakoff that language, when it comes to metaphor, is not our primary tool, there is a deeper sense in which language is secondary to the interaction which produces the metaphor. As long as we do not recognize the primacy of the act over the word, of the body-mind meeting the world over the language accompanying that meeting, it makes no sense to appeal either to 'language' or to 'cognition' and 'reasoning'. Both these activities are derivative, compared to actions in the world. They constitute part of the scene, of the 'speech event' (Hymes) or of the 'activity field' or 'type' (Levinson 1992).

Turning the perspective around, language is more than just a tool. Being born in the meeting between body and world, it is also the

\footnotetext{
5 Not uninterestingly, it should be noted that the idea of a 'fight' as a verbal expression of disagreement in itself is highly suspicious, being characteristic of the particular societies in which it is used; thus, the Friday afternoon discussion sessions at the Institute of the Learning Sciences of Northwestern University, where I used to work in the nineties (just as a decade earlier, similar sessions at Yale University's Department of Computer Sciences, Artificial Intelligence Project), were routinely billed and announced as 'the Friday Fights'. Regularly, one person, usually a graduate student, would submit some of his or her work, to have it then decimated and annihilated by the others present. The idea was not to have any kind of 'truth gathering' or 'mutual inspiration'the essence of these meetings was the fighting ('WAR'), and a good fight was one in which the 'metaphorical' blood was flowing abundantly.
} 
determining factor in future meetings of this kind. It affords us a 'conscientization' (to use Paulo Freire's term) of those meetings, and by doing so, influences the very nature of the interaction. In this sense, language is closer to reality than are the abstract representations we use in modeling our cognitive processes. To vary Pascal, 'language has its reasons that reasoning does not recognize'. That is to say, the view of language as the embodiment, not just of thought, but of thought and action, is ontologically prior to that which abstracts thought from our activities. Language is action, primarily; cognition (including metaphor) abstracts language from its original activity to establish a quasi-independent domain which can 'interact' with other domains, likewise abstracted.

Ironically, Lakoff \& Johnson themselves implicitly recognize that this is the right order of things, when they say (with reference to the metaphoric expression 'time is money'):

"These practices [of quantifying time and associating work with quantified time] are relatively new in the history of the human race, and by no means do they exist in all cultures. They have arisen in modern industrialized societies, and structure our basic everyday activities in a very profound way. Corresponding to the fact that we act as if time is a valuable commodity-a limited resource, even money-we conceive of time that way. Thus we understand and experience time as the kind of thing that can be spent, wasted, budgeted, invested wisely or poorly, saved or squandered" (1980:8; the first set of italics mine, the rest in original). ${ }^{6}$

We see how Lakoff \& Johnson's very notion of 'associating' (in the quote above) implies the act as a presupposition for the conceptualizing. However, they do not stop to consider this simple fact, but proceed as if these processes were happening in the brain only, rather than being 'embodied' in the entire cognizing person. (I will come back to this point in section 5 , below).

\subsection{Spaces and blending}

The reasoning developed above can be applied, mutatis mutandis, to other efforts at mapping human cognitive (including metaphorical) activities

\footnotetext{
6 The German philosopher Alfred Sohn-Rethel has in a number of works (e.g. 1972) drawn our attention to the connection between the invention of money as the 'general equivalent' (some time in the 8th century B.C.) and the rise of 'money consciousness', as among others demonstrated in the metaphors we have constructed on the basis of our monetary activities.
} 
in terms of domain-like structures; I'm thinking here in particular of the notion of 'blending', as it has been developed and practiced (mainly) by Gilles Fauconnier and his followers.

Fauconnier asks himself what happens, when two conceptual domains interfere in mapping out a metaphor, in other words when several conceptual domains blend. That is to say, a particular domain projects itself on/into some other domain, thereby creating an 'integrated mental space', which combines (or 'blends', as Fauconnier calls it) input from various domains, not necessarily unified in character (e.g. lexical, visual, cognitive, etc.; Fauconnier 1995, 1997). The same kind of thinking applies to the representation of grammatical constructions as mappings from one domain, e.g. space, to another, e.g. syntactic or lexical, such as proposed by Langacker (in his theory of Cognitive Grammar; 1987, 1991) and others (such as Leonard Talmy and the Danish school of semiotics).

A nice example of how 'blending' works is provided by Rohrer (1997), a computer scientist whose interests lie in the domain of human-oriented cognitive-technological issues. Rohrer uses the concept to illustrate the effects of simultaneously putting to use two different metaphorical domains: that of time and that of space, when we use the familiar concept of 'the information highway'. If we take space as our basic reference, we will assign the highway a function of leading somewhere in space: for example, when information is transported to sites. But if we use time as our basic point of reference, the movement takes us to some future 'state (or site) of the art', a computational 'nirvana' (Rohrer 1997:8), or 'computopia', as I have called it elsewhere.

Thus, it makes a big difference which activities we choose as the basis for our metaphoring. When it comes to computer technology, adopting one or the other set of metaphorical reasonings, based on appropriate activities, and especially the 'blending' of these activities and reasonings, may have momentous consequences. For instance, in the case of those who use the 'highway' metaphor, expressions such as "bypassing the less fortunate sectors of society" in the name of development, or the creation of a future "information marketplace" (Rohrer 1997:9-10) where the laws of capitalism reign supreme, as they do in the real marketplace, do not just represent activities on the conceptual scene: the effects of the metaphor are felt instantly in those 'sectors' that are 'bypassed', and which see the 
'highway' only as an intrusive monster spreading noise and pollution without benefiting the communities on whose territories they impinge for their 'development'.

\section{The pragmatics of metaphoring}

\subsection{Embodiedmetaphoring}

Ultimately, all metaphors are a kind of 'embodiment': an act by which we make our thoughts and words take bodily shape, making our actions reflect themselves in thoughts and words, and those words and thoughts being 'thrown back' at us through our bodies. This is the dialectic process of mind-body and body-mind meeting the world that was mentioned initially.

Naturally, such a dialectic process of embodiment is not limited to the use and creation of metaphors. The idea of a 'congealed activity', geronnenes Handeln, that Marx talks about, is applicable to our conceptualizing activities in general. And while it is true that conceptualizing 'freezes' the action into one single moment of action-cum-thought, the conceptual 'freeze' constitutes but a moment in our further activities, a stepping stone on to new actions and conceptualizations, including other metaphors. Since, furthermore, our activities are essentially socially based, our conceptualizations must represent the social aspect of our actions. Metaphors are socially important representations of activities that relate to other socially important activities. In other words, they are instances of pragmatic acting.

\subsection{Activity and interaction}

Many current theories of metaphoring emphasize the conceptual side of the metaphorical activity: by establishing conceptual links in our minds, we produce metaphors that shape our actions (thus, e.g., Lakoff \& Johnson 1980, Lakoff 1987, 1993). Other theories, while dealing more or less explicitly with the embodied aspect of our conceptualizations, do not consistently relate this to metaphoring, but talk in a general way about 'analogies' (thus, e.g., Knorr-Cetina in the works cited earlier). 
As stated in the beginning, my view is that metaphors originate in human activity: our actions shape the metaphor and develop it into a cognitive tool. This 'toolness' is realized in what Clark has called an "actionoriented coupling between organism and world" (1997:171); it is on this coupling that the metaphor resides, and to which it ultimately must revert to test its use and usefulness (or lack of the same).

In general, action precedes cognition; cognition is conditioned by action. 'In the beginning was the act', Im Anfang war die Tat, as Goethe admonishes us in his Faust. Moreover, since all human activity is social, action is, in all of its important aspects, always an interaction. "[All] social action is prior to linguistic action", says Greenall, when discussing the Gricean principle of cooperation and its 'flouting' (2002:124); this is true, too, in the case of 'metaphoring'.

When it comes to determine the ways and conditions in which people interact with themselves, one another, and the world, it behooves us to realize that our linguistic activities, in order to yield a useful and respectable product (such as a metaphor), need to be bound into a context of use which respects the conditions of the users, both in the sense that their freedom of action (including that of utterance) is guaranteed, and that there will be a societal wherewithal that allows them to fulfill their linguistic responsibilities. This comprises the 'feasibility' aspect of metaphoring that was discussed previously; it comprises the cases referred to above by the label of 'activity type' (Levinson 1996 [1978]) or the more recent notion of 'pragmatic act' (Mey 2001).

To borrow Greenall's (2002) terminology, even the most 'sedimented', apparently dead, metaphors have their origin in a situation of activity, characterized by certain societal conditions. And even if those conditions do not prevail (or do not prevail any longer), the metaphor, also after its sedimentation, continues to be solidly anchored in its societal situation of origin, such that, at any given time, it can break loose from its petrified moorings, and start interacting again in the former or a new, similar situation-the case of a 'dead' metaphor coming alive again.

And so even the most inveterate city dweller, who never has had a rake in his hands, will be able to 'work' with a metaphoric expression that typically represents country life and farm work. Whoever says: 'Make hay while the sun shines', is using the metaphor of 'haymaking under proper 
conditions' for 'seizing the right time for an activity'. And even though people use this metaphor, and perhaps unconsciously most of their lives, the day may come for the metaphor to be brought back into 'reality', when their attention is caught by some real haymaking, either in the outside world of farming, or as in those famous two chapters of Tolstoy's Anna Karenina, where the protagonist-city man Levin impulsively joins the field laborers in an effort to bring in the hay before the bad weather hits (Part III:ch. 4-5; Tolstoy 1962:278-287).

\subsection{The pragmatics of metaphors}

For a linguist, all metaphors may be created equal, but the reality of metaphoring tells us something different. For example, take Lakoff \& Johnson's famous description of the metaphoric conditions of being 'up' (e.g. as opposed to being 'down', the latter in the sense of: 'being the underdog, depressed, overcome by psychological problems or financial difficulties', and so on. Here, the metaphor may call up situations of activity that most of us probably never have been exposed to, since they reflect (a variation on) an activity type that has gone out of fashion, due to a technological or social development. Nevertheless, this kind of dead or 'sedimented' metaphor (representing Marx's 'congealed activity') can be called up from the dead, and made to flow again, just like the congealed blood of San Gennaro on the streets of Naples, Italy, whenever his feast rolls around on September 19.

Donald A. Schön (in an unfortunately very little quoted article) provides a particularly good example of this kind of 'congealed activity': the 'paint brush as a pump' metaphor (Schön 1993 [1979]). Here, the activity of painting is metaphorically related to the activity of pumping. The force of the 'pump' metaphor resides in its connection to the painting activity that it metaphorically portrays, in sound, feel, and visual perception. The painting person 'knows' when s/he is painting in the right fashion by metaphorically embodying the pump action and the 'feel' and sounds it produces, into his or her painting activity. When the pump goes dry, it makes a horrible, grating sound, and no water will flow; when the paint brush goes dry, it merely scrapes the surface to be painted, and no paint will be transferred. 
Similar metaphoric expressions refer to other typical working situations, as in the 'up-down' dimension, where we find 'top dogs' vs. 'underdogs'. These expressions refer back to an activity in the lumber industry, where large trunks of cut-down trees had to be handled in so-called 'saw pits' for their processing into planks. Basically, such a pit was a rectangular depression, deep enough for a man to stand upright, and long enough to accommodate a sizable chunk of the tree to be cut vertically. The trunk was placed on sawhorses on top of the pit, so that it was not supporting its own weight (which would make the sawing difficult). In this situation, the man on top naturally had the better part: he was standing in fresh air, and didn't have to worry about the saw dust accumulating from under the saw-all of which, along with other detritus, fell down on the bottom sawyer, who naturally and metaphorically was the 'underdog', as opposed to the top sawyer, the 'top dog'. These appellations were in use as long as the working positions of top- vs. bottom sawyer existed; but even after the advent of more mechanized, more (in a certain sense) worker-friendly machinery, the old metaphors stayed on in 'fossilized' form, and subsequently came to be generalized to apply to any situation where one person had all the advantages, the other all the drawbacks.

Quite another type of activity is represented by the metaphoric expression 'sitting at someone's feet', in the sense of: 'being someone's disciple' and collecting wisdom by listening to a guru or other master. This metaphor refers to the pragmatic act of learning, originally executed in a context where the teacher had to sit higher than the students in order to be better seen and understood. 'Sitting at somebody's feet' further implied that in order to best absorb wisdom, one had to be as close to the teacher as possible. And, since the teacher was 'up', one could only get closer by approaching, and finally sitting at, his feet.

And thus it came to be that St. Paul, the former persecutor of the Christians and an apostate in the eyes of the Jews, when he had to defend himself against the angry mob of his former co-religionaries at the Temple Mount in Jerusalem, could establish his credentials by invoking this metaphor, saying that:

"I am verily a man which am a Jew, born in Tarsus, a city in Cilicia, yet brought up in this city at the feet of Gamaliel and taught according to the perfect manner of the law of the fathers,..." (Acts 22:3) 
- Gamaliel being the most respected rabbinical theologian of his day, an authority who even today is still quoted throughout the Jewish world of Talmudic studies.

The interesting thing about this metaphor ('being brought up at somebody's feet') is that it has been kept alive, down through the millennia, to characterize this pragmatic act of learning, as embodied in the metaphor, even though over the centuries, the original situation has drastically changed. Today, a similar metaphor would probably have a hard time getting 'sedimented', what with the ubiquity of electronic teaching devices such as employed in 'education at a distance' through 'universities of the air', in 'edutainment' techniques, and other depersonalizing educational practices.

\section{Conclusion: The socially embodied metaphor}

Metaphors embody our activities, the way we socially interact with the world. By the same token, they indicate what value society puts on those activities, in which terms society interprets our actions, and towards what goals it allows us to operate.

Thus, as we have seen, all metaphors necessarily have their origin in some relevant, 'worldly' activity; one cannot construe a metaphor out of a domain of activity that is not, or no longer, relevant to a particular culture or society. (However, 'sedimented' metaphors are often allowed to continue representing earlier stages of human activity, even though the activities themselves are no longer relevant).

Turning the perspective around, we have seen how certain activity domains have built-in conditions and constraints that are related to the use we make of the domain, or to the values the domain is accorded in our societal system. Here are some examples:

Most money-related or money-oriented metaphors make sense only if contextualized in the Western capitalist mode of production, as in "Does your money work for you or does it just sit there?" (like a 'nest egg'; from a promotional blurb for Connecticut State Bank, New Haven, in the eighties). 
Another, very strong and pervasive usage of metaphors is that corresponding to the activities involved in life itself and its opposite, death. Compare a 'live wire', 'deadhead train', 'dying' initiatives, the 'half-life' of a radioactive substance, the 'living' word or spirit vs. the 'dead' letter; the 'lively' vs. the 'sluggish stock market'; and so on.

One of the most important domains of current human activity is that of computers; consequently, the ways society allows us to metaphorize computer and computer related activities turn out to be extremely relevant for our purpose.

Computers were originally definitely not metaphorical instruments, but fast, straightforward aids in calculating arithmetic or symbolic functions that otherwise would have taken us years and years to perform. In the educational domain, this 'ancillary' period was characterized by CAI tests and quizzes on the computer, with their mindless drills, small remunerations, and Skinnerian perspectives of encouraging the users/ students. Tests came to replace learning as an educational goal (Schank 2001). The computer itself was depicted as an assistant, visualized as a pop-up wizard, a paper clip man and many other rather strange, human or humanoid, incarnations. ('Ask Ken, the agent'; 'Hi, I'm Super-Dog').

At the far end of this 'assisting' domain, we have the computer as physiological (or even intelligent) being. Here, the meeting of the bodymind with the world is itself 'embodied' in an object, and this 'objectified' metaphor is endowed with life and thought and their corresponding activities, such that the interaction can start anew, this time on a 'metaplane', where computers interact with other computers, and so ad infinitum (or until somebody says 'Stop!').

In this context, the main metaphorical question becomes: Who or which is a metaphor for what or whom?

This question can be made more concrete by asking two supplementary questions:

First, what kinds of metaphors for human activities does the computer embody?

And second, following up on that question, its converse: 
Do human activities (and which) become an embodied metaphor of computer(ized) action?

In this latter sense, the question is if, and to what extent, the computer is turning us into computerized metaphors of ourselves. In particular, one could as what it would mean, or imply, to consider humans as being (metaphors of) machines? For instance, what does it imply to say that implicatures are 'wired into the brain' (a technological metaphor), or that our cognitive activities should be related to, and figured in terms of, economic machinery such as input, output, and processing costs (expressions widely found in the literature on Cognitive Linguistics and Relevance Theory)?

The crucial moment of truth (and danger) occurs when we stop realizing that what we are talking about are no longer computers or humans, but humans that we consider as playing a 'computerized' role in our lives. That is, when we no longer think of the computer as a metaphor for the brain, but maintain that the brain is a computer, some kind of biological hardware ('wetware' or 'mindware'), susceptible to programming, and executing the same functions that 'real' computers have. The inevitable next step will then be that we simply relinquish control and assume that the computerized mind will be 'better' equipped to cope with the functions that the oldfashioned mind no longer can fulfill, a bit like the computers that control the launching and landing of a spacecraft or a carrier-based airplane.

When the computers take over, their ancillary status of representing or embodying a metaphor is converted to a permanent and irrevocable substitution of the computer for a human agent. The word has once more become flesh; or rather, in this case, a bunch of interconnected, printed circuits. The human is reincarnated in the computer, as his/her own 'wired' metaphor. Electronically simulated wetware may now replace the brain, while the mind ends up as a super-constellation of macros called 'mindware', which is basically nothing but an embodied metaphor, representing a mutually firing, conceptually enriched system of interconnected neurons (Clark 2001).

However, even when the computer-metaphor has adopted human flesh, the main question still remains who is in control of the new embodiment. This is the problem that any future theory of metaphor which bases itself on human activity will have to address.

E-mail: jam@mail.dou.dk 


\section{REFERENCES}

Clark, Andy. 1997. Being there: Putting brain, body, and world together again. Cambridge, Mass.: MIT Press. . 2001. Mindware. Cambridge: Cambridge University Press.

FAUCONNIER, Gilles. 1995. Mental spaces: Aspects of meaning construction in natural language. Cambridge: Cambridge University Press. 1997. Mappings in thought and language. Cambridge: Cambridge University Press.

Greenall, Ann Jorid Klungervik. 2002. Towards a socio-cognitive account of flouting and flout-based meaning. Trondheim: Norwegian University of Science and Technology. (Ph.D diss.)

Hanks, William F. 1996. Language and communicative practices. Boulder, Colo.: Westview Press.

Knorr-Cetina, Karin. 1981. The manufacture of knowledge. Oxford: Pergamon. . 1999. Epistemic Cultures. How the sciences make knowledge. Cambridge, Mass., \& London: Harvard University Press.

LakOFF, George. 1987. Women, fire and dangerous things. Chicago: University of Chicago Press.

1993. 'The contemporary theory of metaphor'. In: A. ORTONY, ed. pp. 202-251. \& Mark Johnson. 1980. Metaphors we live by. Chicago: University of Chicago Press.

LANGACKer, Ronald W. 1987/1991. Foundations of cognitive linguistics I/II. Stanford: Stanford University Press.

Levinson, Stephen C. 1983. Pragmatics. Cambridge: Cambridge University Press.

1996. 'Activity types and language'. In: Paul Drew \& John Heritage (eds.) Talk at work. Cambridge: Cambridge University Press. pp. 66-100. [1978] 2000. Presumptive meanings: The theory of Generalized Conversational Implicatures. Cambridge, Mass.: MIT Press.

Mey, Jacob L. 1987. 'CAIN and the transparent tool'. Proceedings Third Symposium on Human Interface. Osaka/Tokyo: Journal of the Society of Instrument and Control Engineers 27(1).

. 1996. 'Cognitive technology - Technological cognition'. AI $\varepsilon$ Society 10:226-232. 
2001. Pragmatics: An introduction. Oxford \& Boston: Blackwell Publishers. (Second edition) [1993]

. 2002. 'Tool, instrument, artifact? The cognitive computer'. RASK: International Journal of Language E Communication 17:99-118.

OrTONy, Andrew, ed. 1993. Metaphor and thought. Cambridge: Cambridge University Press. (Second edition) [1979]

RoHrer, Tim. 1997. 'Conceptual blending on the information highway: How do metaphorical inferences work?' In: Discourse and perspective in Cognitive Linguistics. Amsterdam: John Benjamins.

Schank, Roger C. 2001. Scrooge meets Dick and Jane. Hillsdale, N.J.: Erlbaum. Schön, Donald. 1993. 'Generative metaphor: A perspective on problemsetting in social policy'. In: A. Ortony (ed.). pp. 138-163.

Sohn-Rethel, Alfred. 1972. Geistige und körperliche Arbeit. Frankfurt am Main: Suhrkamp. (Abridged in English as 'Intellectual and manual labour: An attempt at a materialistic theory'. Radical Philosophy 6: 30-37).

Tolstoy (Tolstoj), Lev S. 1962. Anna Karenina, Vol. I. Moscow: Izdatel'stvo Pravda. [1889] 